\title{
Formation of Single-Crystalline Aragonite Tablets/Films via an Amorphous Precursor
}

\author{
Fairland F. Amos, ${ }^{\dagger}$ Denise M. Sharbaugh, ${ }^{\ddagger}$ Daniel R. Talham ${ }^{\ddagger}$ and Laurie B. Gower ${ }^{*}+$ \\ Departments of Materials Science and Engineering, and Chemistry, University of Florida, P.O. Box \\ 116400, Gainesville, Florida 32611, USA \\ Marc Fricke, Dirk Volkmer
}

Faculty of Chemistry (AC 2), University of Ulm, Albert-Einstein-Allee 11, D-89081 Ulm (Germany)

\footnotetext{
* Corresponding author: fax (+01) 352-846-3355; email lgowe@mse.ufl.edu

${ }^{\dagger}$ Department of Materials Science and Engineering

$\$$ Department of Chemistry
} 


\section{SUPPORTING INFORMATION}

Supporting Figure 1 shows the LC domains, as well as bright spots, on the resorcarene monolayer that is spread over $10 \mathrm{mM} \mathrm{CaCl}_{2}, 10 \mathrm{mM} \mathrm{MgCl}_{2}$ and $4 \mu \mathrm{g} / \mathrm{mL}$ PAA. Even in the absence of a $\mathrm{CO}_{3}{ }^{2-}$ counterion, bright spots are still observed, implying that these spots are not $\mathrm{CaCO}_{3}$ but are cationmonolayer complexes.

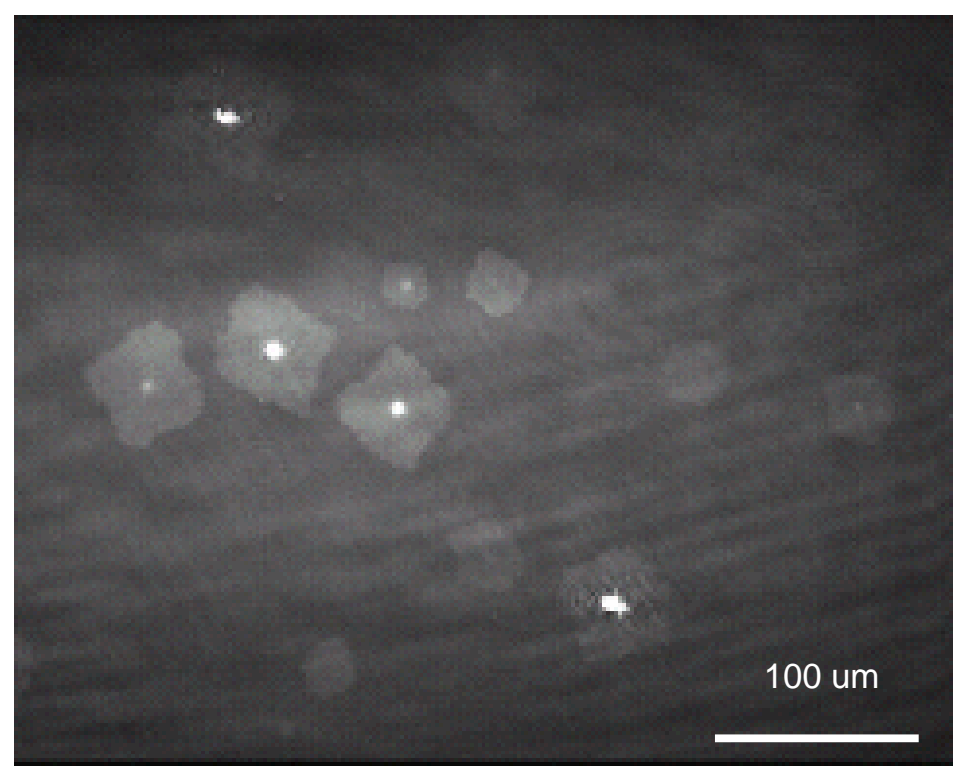

Supporting Figure 1. Brewster angle micrograph of the resorcarene monolayer on $10 \mathrm{mM} \mathrm{CaCl}, 10$ $\mathrm{mM} \mathrm{MgCl} 2$ and $4 \mu \mathrm{g} / \mathrm{mL}$ PAA subphase, at a pressure higher than the LE/LC phase transition. 
The polymorph of various single-crystalline patches on the resorcarene monolayer formed in the aragonite/calcite window (Figure 7 in main text) were analyzed using selected area electron diffraction. Eleven of 20 single-crystalline tablets analyzed were unambiguously aragonite; the rest were calcite. Supporting Figure 2 shows one of those patterns that are unambiguously aragonite.

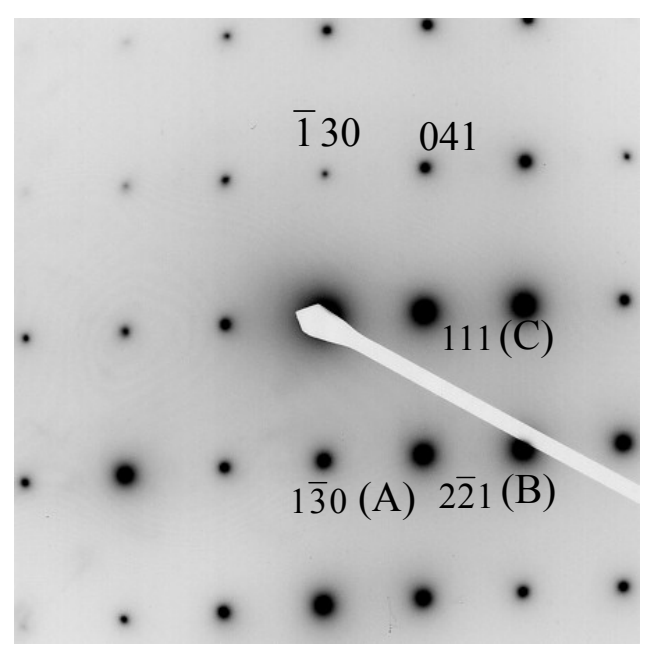

Supporting Figure 2. Aragonite pattern from a single-crystalline patch grown on the resorcarene monolayer from Solution 3. Zone axis at $[\overline{3} \overline{1} 4]$. Indices are based on JCPDS 41-1475. Markers (AC) are used for comparison with the theoretical d-spacings and angles presented in Supporting Table 1. 
Supporting Table 1. Comparison of the experimental and theoretical d-spacings of, and angles between, the spots for the aragonitic diffraction pattern in Supporting Figure 2.

\begin{tabular}{|c|c|c|c|}
\hline Solution 3 & $\begin{array}{c}\text { Experimental } \\
\text { values }\end{array}$ & $\begin{array}{c}\text { Theoretical values } \\
\text { for aragonite }\end{array}$ & $\begin{array}{c}\text { Assignment of } \\
\text { peaks }\end{array}$ \\
\hline $\mathrm{d}(\mathrm{A})$ & $2.295 \AA$ & $2.341 \AA$ & $(1 \overline{3} 0)$ \\
\hline $\mathrm{d}(\mathrm{B})$ & $1.944 \AA$ & $1.977 \AA$ & $(2 \overline{2} 1)$ \\
\hline $\mathrm{d}(\mathrm{C})$ & $3.366 \AA$ & $3.396 \AA$ & $(111)$ \\
\hline$\theta(\mathrm{A}-\mathrm{B})$ & $36.0^{\circ}$ & $35.5^{\circ}$ & \\
\hline$\theta(\mathrm{A}-\mathrm{C})$ & $57.0^{\circ}$ & $57.5^{\circ}$ & \\
\hline$\theta(\mathrm{B}-\mathrm{C})$ & $93.0^{\circ}$ & $93.0^{\circ}$ & \\
\hline
\end{tabular}


We estimated the surface area (and from this data, the volume) occupied by the aggregates (B) and the films (F). In this method, optical images of the sample were divided into 50 x $50 \mu \mathrm{m}^{2}$ grids, as shown in Supporting Figure 3. The number of hits of each species on the grid intersection divided by the total number of intersections represents the area fraction occupied by that species. For completeness, we have to account for the area on the air-water interface that is not covered by the mineral, which we define as area covered by water (W). Twenty images were analyzed to statistically determine the area fraction at a particular mineralization time.

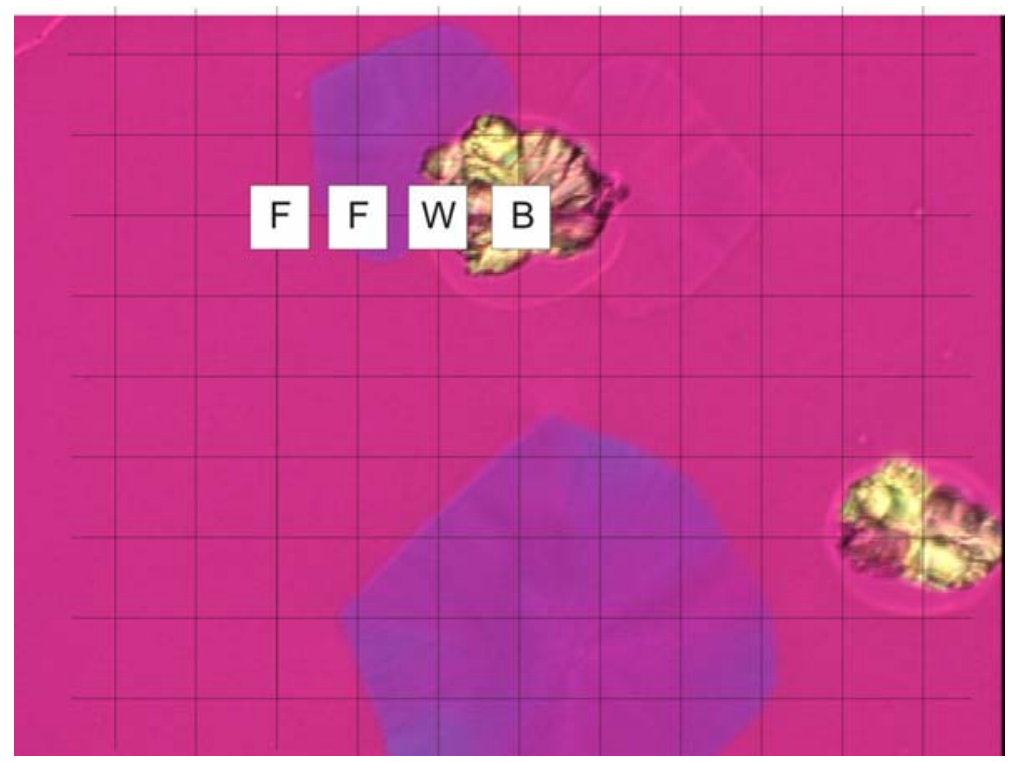

Supporting Figure 3. Micrograph of the $\mathrm{CaCO}_{3}$ formed on the resorcarene monolayer using Solution 3, the solution that yields both calcite and aragonite tables. The image was divided into sections for surface-area estimation of the mineral species (B: bulk crystals or aggregates; F: films). Areas that are not covered by the mineral are denoted as W (water). The dimensions of each grid is $50 \times 50 \mu \mathrm{m}^{2}$. The analyzed area is $450 \times 550 \mu^{2}$.

Using this technique, we were able to approximate the relative surface area of the aggregates $(8 \%)$, ACC films (69\%), crystalline films (12\%) and water (11\%). Calculating the volume of the film, 


$$
\begin{aligned}
V_{\text {film }} & =x_{\text {film }} * A_{\text {dish }} * t_{\text {film }}=x_{\text {film }} * \pi * r_{\text {dish }}^{2} * t_{\text {film }} \\
V_{\text {film }} & =0.12 * \pi *(3 \mathrm{~cm})^{2} *(600 \mathrm{~nm}) \\
V_{\text {film }} & =0.204 \mathrm{~mm}^{3}
\end{aligned}
$$

where $V_{\text {film }}$ is the volume of the film after 2 days of mineralization, $x_{\text {film }}$ is the surface area fraction occupied by the film, $A_{\text {dish }}$ is the surface of the Petri dish, $t_{\text {film }}$ is the thickness of the film after 2 days and $r_{\text {dish }}$ is the radius of the Petri dish. Note that in this solution, both calcite and aragonite tablets are formed; thus the volume of the aragonite tablets has an upper value of $0.204 \mathrm{~mm}^{3}$.

Estimating the volume of the aggregates,

$$
\begin{aligned}
& A_{\text {bulk,total }}=n * A_{\text {bulk,each }}=x_{\text {bulk }} * A_{\text {dish }} \\
& n * \pi * r_{\text {bulk,each }}{ }^{2}=x_{\text {bulk }} * \pi * r_{\text {dish }}{ }^{2} \\
& r_{\text {bulk,each }}=\left(\frac{x_{\text {bulk }}}{n}\right)^{1 / 2} r_{\text {dish }} \\
& V_{\text {bulk,total }}=n * V_{\text {bulk,each }}=n * \frac{4}{3} \pi\left(\frac{x_{\text {bulk }}}{n}\right)^{3 / 2} r_{\text {dish }}{ }^{3}
\end{aligned}
$$

where $A_{\text {bulk,total }}$ is the total surface area covered by the aggregates, $n$ is the total number of aggregates in the Petri dish, $A_{b u l k, e a c h}$ is the surface area covered by an individual aggregate, $x_{b u l k}$ is the surface area fraction occupied by the aggregates, $r_{\text {bulk,each }}$ is the radius of an individual aggregate, $V_{b u l k, t o t a l}$ is the volume of the total aggregates and $V_{\text {bulk,each }}$ is the volume of an individual aggregate. In the 20 optical images analyzed, 38 aggregates were observed (2 aggregates are found in Supporting Figure 3). To determine the total number of aggregates in the Petri dish, we scaled the number of aggregates found in the 20 optical images relative to the area of the Petri dish (each optical image has an analyzed area of 450 x $550 \mu \mathrm{m}^{2}$, as seen in Supporting Figure 3).

$$
\begin{aligned}
& \frac{n}{A_{\text {dish }}}=\frac{n_{\text {20images }}}{A_{\text {20images }}} \\
& n=\left(\frac{38}{20 * 450 \mu \mathrm{m} * 550 \mu \mathrm{m}}\right) * \pi(3 \mathrm{~cm})^{2}, \\
& n=21706
\end{aligned}
$$


where $n_{\text {20images }}$ is the number of aggregates observed in the 20 optical images and $A_{20 i m a g e s}$ is the total area of 20 optimal images analyzed. Thus,

$$
\begin{aligned}
V_{\text {bulk,totol }} & =21706 * \frac{4}{3} \pi\left(\frac{0.08}{21706}\right)^{3 / 2}(3 \mathrm{~cm})^{3} \\
V_{\text {bulk,total }} & =17.4 \mathrm{~mm}^{3}
\end{aligned}
$$

This indicates that the volume of the crystalline films is 100 -fold less than that of bulk aggregations, which may translate into a lack of XRD signal from the crystalline films. 
Different monolayer systems, such as arachidic acid and phosphatidylcholine, were also used as substrates for $\mathrm{CaCO}_{3}$ mineralization. Single crystalline patches of calcite and aragonite were observed on the arachidic acid monolayer. Supporting Figure 4 shows a bright-field image and the corresponding SAED of a single-crystalline aragonite patch. No single crystalline patches were observed on the phospholipid monolayer used.
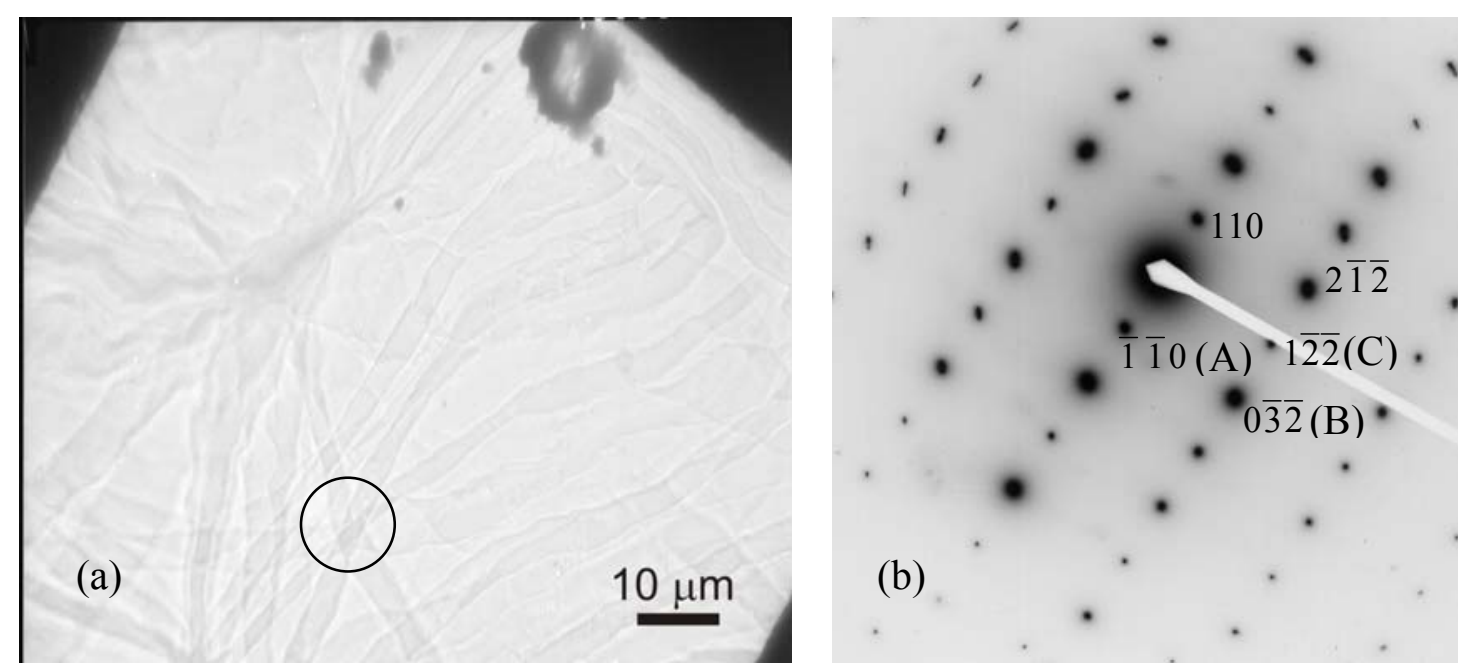

Supporting Figure 4. (a) Bright-field image of a single crystalline patch of aragonite film grown on an arachidic acid monolayer in the presence of $\mathrm{Mg}^{2+}$ and PAA. The dark regions are edges of the TEM grid. (b) Selected area electron diffraction pattern of the encircled region in (a) which matches aragonite. 
Supporting Table 2. Comparison of the experimental and theoretical d-spacings of, and angles between, the diffraction maxima spots for the aragonitic diffraction pattern in Supporting Figure $4 \mathrm{~b}$.

\begin{tabular}{|c|c|c|c|}
\hline Solution 2 & $\begin{array}{c}\text { Experimental } \\
\text { values }\end{array}$ & $\begin{array}{c}\text { Theoretical values } \\
\text { for calcite }\end{array}$ & $\begin{array}{c}\text { Assignment of } \\
\text { peaks }\end{array}$ \\
\hline $\mathrm{d}(\mathrm{A})$ & $4.210 \AA$ & $4.211 \AA$ & $(\overline{1} \overline{1} 0)$ \\
\hline $\mathrm{d}(\mathrm{B})$ & $1.891 \AA$ & $1.949 \AA$ & $(0 \overline{3} \overline{2})$ \\
\hline $\mathrm{d}(\mathrm{C})$ & $2.107 \AA$ & $2.108 \AA$ & $(1 \overline{2} \overline{2})$ \\
\hline$\theta(\mathrm{A}-\mathrm{B})$ & $65^{\circ}$ & $67^{\circ}$ & \\
\hline$\theta(\mathrm{A}-\mathrm{C})$ & $92^{\circ}$ & $95^{\circ}$ & \\
\hline$\theta(\mathrm{B}-\mathrm{C})$ & $27^{\circ}$ & $27^{\circ}$ & \\
\hline
\end{tabular}


SYNOPSIS TOC. Using appropriate concentrations of polyanionic polymer and $\mathrm{Mg}^{2+}$ processdirecting agents, a polymer-induced liquid-precursor (PILP) mineralization process is used to deposit $\mathrm{CaCO}_{3}$ films and tablets onto a resorcarene monolayer template. The biomimetic mineral emulates the morphology and phase of the single-crystalline aragonite pseudohexagonal tablets found in mollusk nacre.

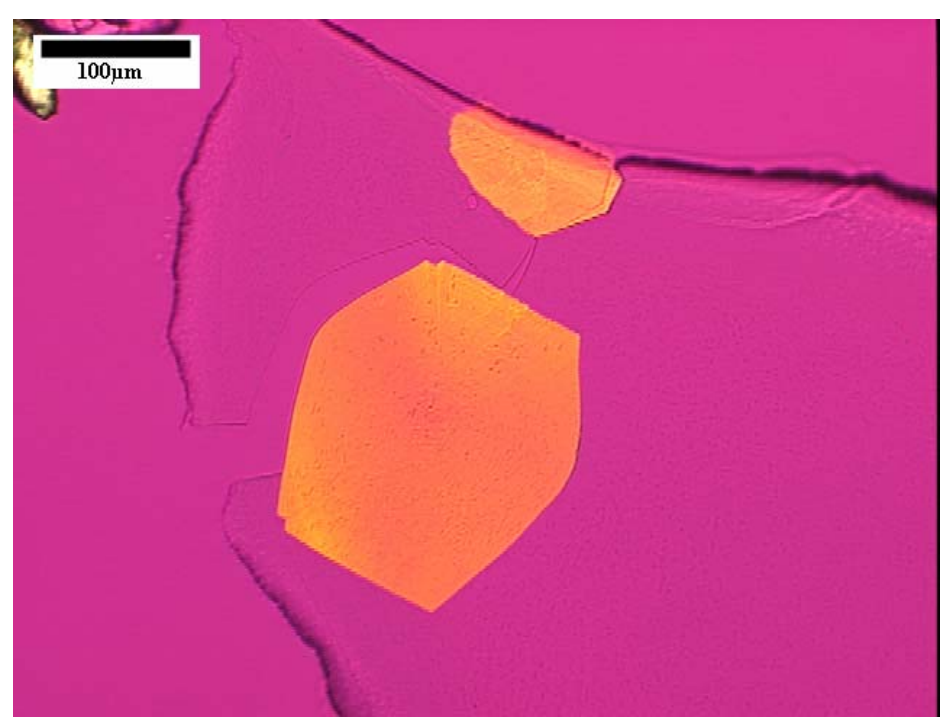

